\title{
Review Article \\ Influence of Hydrocolloids on the Quality of Major Flat Breads: A Review
}

\author{
Akanksha Pahwa, ${ }^{1}$ Amarjeet Kaur, ${ }^{1}$ and Ritika Puri ${ }^{2}$ \\ ${ }^{1}$ Department of Food Science and Technology, Punjab Agricultural University, Ludhiana, Punjab 141004, India \\ ${ }^{2}$ Dairy Technology Division, ICAR-National Dairy Research Institute, Karnal, Haryana 132001, India \\ Correspondence should be addressed to Ritika Puri; ritikadsweet@gmail.com
}

Received 31 August 2015; Revised 26 November 2015; Accepted 13 December 2015

Academic Editor: Franco P. Pedreschi

Copyright (c) 2016 Akanksha Pahwa et al. This is an open access article distributed under the Creative Commons Attribution License, which permits unrestricted use, distribution, and reproduction in any medium, provided the original work is properly cited.

\begin{abstract}
Flat breads are popular all over the world. There are several forms of flat bread, which differ in their methods of preparation. In comparison to pan breads, the leavened flat breads have shorter fermentation period. Nowadays, the use of additives has become a common practice in the baking industry. In this paper, supplementation of several hydrocolloids having different chemical structure and diverse origin to the flatbread making process is presented. Hydrocolloids comprise a number of water-soluble polysaccharides providing a range of functional properties that make them suitable to this application. They provide proper texture, control moisture, improve overall product quality and stability, reduce cost, and facilitate processing in the flat breads. Various gluten-free formulations have applied hydrocolloids to mimic the viscoelastic properties of gluten. Hydrocolloids have been used for retarding the staling and for improving the quality of the fresh products. In addition to this, good sensory properties for visual appearance, aroma, flavor, crunchiness, and overall acceptability were obtained.
\end{abstract}

\section{Introduction}

In India, Pakistan, Middle East, and North African countries, a large segment of population depends upon whole wheat meal (atta) for production of "chapattis," whereas refined flour (maida) finds greater application in manufacture of bakery products, for example, breads and biscuits. Wheat (Triticum aestivum) is a common ingredient used in many types of flat breads due to the special functional properties of its constituent protein, gluten. Improving the nutritional value of bread with whole grains has become popular due to its documented positive health effects. The replacement of gluten presents a major technological challenge, as it is an essential structure-building protein. To tackle this problem, hydrocolloids like xanthan gum and guar gum were incorporated in gluten-free flour to mimic the viscoelastic properties of gluten [1].

(1) Effects of Hydrocolloids on Pasting Properties of Starch Granules. Nonstarch polysaccharides used in formulated food systems are usually called hydrocolloids. Starches and gums (hydrocolloids) are often used together in food systems to provide proper texture, control moisture, and water mobility, improve overall product quality and/or stability, reduce cost, and/or facilitate processing. It is therefore important to understand interactions between starches and food gums that are critical to the functionalities they impart to food products [2]. Hydrocolloids modify gelatinization of starch and extend the overall quality of the product during storage [3].

Hydrocolloid molecules have a variety of different structures, including differences in branching, flexibility, molecular weight ranges, and ionic charge, all of which influence their behaviour and the rheology of their solutions. This also influences their interaction with leached starch polymer molecules which in some cases increases network formation and in other cases decreases or weakens the network formed by starch polymer molecules. In the rapid-visco-analyser, pasting occurs with continued heating (normally to a $95^{\circ} \mathrm{C}$ hold temperature) under the shear of the instrument till all order is lost in granules. During pasting, considerable granule swelling and leaching of starch polymer (primarily amylose) molecules occur. A peak viscosity, primarily resulting from 
swollen granules, is reached. During the $95^{\circ} \mathrm{C}$ hold, the fragile swollen granules disintegrate under the shear conditions of the instrument, and the viscosity decreases to a trough viscosity (a process called breakdown). As the hot pastes, especially of amylose-containing starches, begin to cool, they become more elastic and develop distinct solid properties; that is, gelation occurs. The transition from a viscous liquid to a gel, when determined by one of the instruments, is called setback; the molecular process that produces setback is known as retrogradation [4].

The hydrocolloid reduced the availability of water for granule swelling. The increased viscosity thereby increased the shear forces exerted on the swollen granules, thus increasing the breakdown viscosity. Associations between starch polymer molecules and hydrocolloid molecules could be responsible for increase in setback and final viscosity. Hydrocolloid molecules bound water reduced the mobility of the starch chains and thereby retard retrogradation [5]. Effects of guar (GG) and xanthan (XG) gums $(0.35-1.0 \%$ $\mathrm{w} / \mathrm{w})$ on pasting and rheological properties of waxy corn starch (WCS) $(6.0 \% \mathrm{w} / \mathrm{w})$ were studied by Achayuthakan and Suphantharika [6]. Rapid-visco-analyser results indicated that addition of GG or XG to WCS significantly $(P \leq 0.05)$ increased the peak, breakdown, final and setback viscosities, and pasting temperatures. This effect was more pronounced as the concentrations of GG or XG increased. GG had a higher molecular weight but lower intrinsic viscosity than did XG; thus GG chain was more flexible (Table 1).

Increased peak viscosity was more pronounced for the WCS/GG than in the WCS/XG mixtures at high gum concentrations $(0.7 \%$ and $1.0 \%)$ (Table 2$)$.

This could be attributed to the fact that XG covered most of the starch granules individually. GG, on the contrary, did not cover the starch granules but formed a sheet structure in the continuous phase. Dynamic viscoelasticity measurements indicated that the WCS/XG mixed pastes exhibited slightly superior viscoelastic properties to the WCS/GG pastes as evidenced by their higher $G^{\prime}$ and lower $\tan \delta$ values. Flow tests showed that the WCS/GG pastes exhibited mainly thixotropic hysteresis loops during a full shear cycle, whereas the WCS/XG pastes showed much less thixotropic and eventually became antithixotropic at high XG concentrations. The differences in molecular characteristics of the GG and $X G$ chains are hypothesized to be responsible for the above-mentioned effects. Effects of various hydrocolloids like hydroxypropyl methylcellulose (HPMC), xanthan, and $\kappa$ carrageenan at 0.2 and $0.5 \%$ levels were investigated on dough rheological properties [7]. Dough water absorption increased by all hydrocolloids tested. Except $\kappa$-carrageenan, all the hydrocolloids resulted in increase in dough development time (DDT). Only xanthan addition at $0.5 \%$ level showed an increase in dough stability, while the other treatments showed a reduction in the stability of the dough (Table 3 ). At all levels of incorporation of guar gum (0-1\%), it was observed that water absorption and dough stability increased with increase in concentration of guar gum. With respect to dough development time, it was found to be correlated inversely with the concentration of guar gum [8]. Incorporation of hydrocolloids like pectin, carboxymethyl cellulose (CMC),
TABLE 1: Molecular weight and intrinsic viscosity of guar gum (GG) and xanthan [6].

\begin{tabular}{lcc}
\hline Sample & Molecular weight $(\mathrm{Da})$ & Intrinsic viscosity $(\mathrm{dL} / \mathrm{g})$ \\
\hline GG & $6.12 \times 10^{6}$ & 9.4 \\
XG & $3.47 \times 10^{6}$ & 112.3 \\
\hline
\end{tabular}

agarose, xanthan, and oat $\beta$-glucan revealed that xanthan gum yielded the most strengthened dough [1].

(2) Effects of Hydrocolloids on the Gluten-Free Bread. The quality of gluten-free bread obtained by adding pectin, guar gum, and their 1:1 mixtures was compared [9]. Gluten was replaced by highly methylated pectin in standard bread. Breads containing guar gum had higher volume, moisture content of crumb, baking efficiency, and lower oven loss. Texture profile analysis revealed that use of guar gum and pectin in 1:1 reduced gumminess and chewiness of guar bread. This treatment also reduced crispiness and resilience of pectin bread. Hardening was highest for guar bread due to starch gelatinization and lowest for breads with mixture of guar gum and pectin.

Study was conducted by Guarda et al. [10] to analyze the influence of hydrocolloids (sodium alginate, xanthan, $\kappa$ carrageenan, and hydroxypropyl methylcellulose) on fresh bread quality and bread staling. All-purpose flour was partially replaced with locust bean gum (LBG) and guar gum at $0 \%$ (control), $2 \%$, and $4 \%$ replacement levels. These bread treatments were evaluated objectively and subjectively by Schwarzlaff et al. [11]. LBG replacement at $2 \%$ significantly increased standing height. Moisture, crumb, and crust colour were not significantly different. At $2 \%$ level, guar gum produced a more even cell size distribution throughout the bread crumb. Both gums were found to retard bread staling; 2\% LBG was the most effective.

Effect of hydrocolloids on dough rheology and bread quality parameters in gluten-free formulations based on rice flour, corn starch, and sodium caseinate (control) was discussed by Lazaridou et al. [1]. The hydrocolloids added at $1 \%$ and $2 \% \mathrm{w} / \mathrm{w}$ (rice flour basis) were pectin, carboxymethyl cellulose (CMC), agarose, xanthan, and oat $\beta$-glucan. Farinograph showed that xanthan had the most pronounced effect on viscoelastic properties yielding strengthened doughs. Addition of hydrocolloids showed that the elasticity and resistance to deformation of dough, as determined by oscillatory and creep measurements, followed the order of xanthan $>$ $\mathrm{CMC}>$ pectin $>$ agarose $>\beta$-glucan. Aspects considered included specific hydrocolloid used and its concentration, bread loaf volume, porosity, crumb elasticity, lightness of crust, and crumb firmness. High values of porosity were found for breads supplemented with CMC and beta-glucans at $1 \%$ concentration and pectin at $2 \%$, whereas high crumb elasticity was exhibited by CMC, pectin, and xanthan at $2 \%$. An increase in lightness ( $L^{*}$ value) of crust was observed with the addition of beta-glucan at $1 \%$, whereas the whiteness of crumb was improved with inclusion of xanthan. No significant effect on water activity of crumb was observed. 
TABLE 2: Pasting properties of $6 \% \mathrm{w} / \mathrm{w}$ waxy corn starch (WCS) in the presence of various concentrations of guar gum (GG) or xanthan gum (XG) [6].

\begin{tabular}{lccc}
\hline Sample & Gum concentration $(\%)$ & Peak viscosity $(\mathrm{RVU})$ & Pasting temperature $\left({ }^{\circ} \mathrm{C}\right)$ \\
\hline WCS/water & 0.00 & 133.4 & 71.3 \\
WCS/GG & 0.35 & 162.2 & 75.1 \\
WCS/GG & 0.75 & 236.6 & 85.8 \\
WCS/GG & 1.00 & 245.8 & 83.4 \\
WCS/XX & 0.35 & 168.6 & 82.3 \\
WCS/XX & 0.70 & 174.8 & 80.7 \\
WCS/XX & 1.00 & 224.2 & 82.1 \\
\hline
\end{tabular}

TABLE 3: Farinograph parameters of gluten-free dough [1].

\begin{tabular}{lccc}
\hline Dough formulations & Water absorption (\%) & DDT (min) & Elasticity (BU) \\
\hline Without hydrocolloid & 60.5 & 4 & 60 \\
Pectin & 65.2 & 10.5 & 60 \\
Carboxymethyl cellulose & 63.4 & 26.5 & 70 \\
Agarose & 65.0 & 7.5 & 40 \\
Xanthan & 67.0 & 2.0 & 100 \\
\hline
\end{tabular}

Effect of composition of hydrocolloids (pectin, guar gum, and xanthan gum) on properties of gluten-free bread was reported by Gambus et al. [12]. Xanthan gum produced higher volumes. Lowest hardness was observed for crumb with the smallest addition of xanthan gum. It influenced cohesiveness to a lesser extent. The amount of free amylose in crumb extract depended on the extent of starch gelatinisation, influenced by proportions of pectin, guar gum, and xanthan in the mixture of hydrocolloids.

Influence of hydroxypropyl methylcellulose (HPMC), xanthan gum, and their combination on characteristics of gluten-free breads, prepared with rice, maize, teff, and buckwheat was studied by Hager and Arendt [13]. HPMC had a positive linear effect on volume of teff breads and a negative linear effect on this parameter in rice breads, while the volume of buckwheat bread did not change. For maize breads, volume was increased by addition of HPMC. Xanthan addition had a negative linear effect on loaf volume of all breads. Xanthan increased the crumb hardness of teff and buckwheat breads, while rice bread crumb remained uninfluenced. HPMC addition reduced crumb hardness of teff, buckwheat, and maize and rice bread. Also crumb grain characteristics such as area of cells and wall thickness were influenced by the hydrocolloids. Optimal level of water and hydrocolloid was determined using optimization trials.

(3) Effect of Hydrocolloids on Gluten Characteristics. The nature of protein-polysaccharide interactions can vary widely due to wide variations in biopolymer structure and solvent conditions. Depending on these conditions, macromolecular interactions may be specific or nonspecific, weak or strong, and repulsive or attractive [14].

León et al. [15] found that hydrophobic amino groups of glutamines present in the gluten protein interacted with sulphate groups of $\lambda$-carrageenan.
The effects of hydrocolloids on the functional properties of dough and bread quality depend on the nature, origin, and particle size of the hydrocolloid and the dosages of the hydrocolloid incorporated into dough formulations.

Influence of three hydrocolloids (Arabic gum, pectin, and HPMC) on characteristics of gluten was observed [16]. Gluten characteristics were hydration properties (swelling, water retention capacity, and water binding capacity) (Table 4 ), gluten quality (gluten index, the amount of wet and dry gluten), protein sodium dodecyl sulphate extractability, and rheological properties (elastic and viscous moduli). Results revealed that gluten properties were affected by hydrocolloids to different extent depending on the type and concentration of hydrocolloid, which was dependent on the hydrocolloid type and also its concentration (Table 4). With respect to HPMC, it was found that there is an initial interaction between this hydrocolloid and gluten proteins that decrease the interaction with the water molecules, but when the level of the hydrocolloid was increased it acquires a predominant role in binding water molecules. Formation of electrostatic complexes between anionic hydrocolloids, like pectin, and gluten could be responsible for increased water binding capacity [17]. All the hydrocolloids, with the exception of Arabic gum, decreased the viscoelastic moduli during heating and cooling, yielding a weakening effect on gluten. Pectin mainly acted on gluten properties, varying gluten hydration, and also the quantity and quality of gluten.

(4) Effect of Hydrocolloids on Storage Stability of Breads. The difficulty in finding gluten-free bread and its high price makes it necessary to prolong its shelf life to facilitate its availability. Hydrocolloids are widely used as additives in the food industry, because they are useful for modifying the rheology and texture of aqueous suspensions. Hydrocolloids due to their high water retention capacity confer stability 
TABLE 4: Hydration properties of hydrated vital gluten in the presence of hydrocolloids.

\begin{tabular}{lcccc}
\hline Sample & $\begin{array}{c}\text { Hydrocolloid level } \\
\text { (g/g gluten })\end{array}$ & $\begin{array}{c}\text { Swelling } \\
(\mathrm{mL} / \mathrm{g})\end{array}$ & $\begin{array}{c}\text { Water holding capacity } \\
\text { (g water/g solid) }\end{array}$ & $\begin{array}{c}\text { Water binding capacity } \\
\text { (g water/g solid) }\end{array}$ \\
\hline Control & 0.000 & 4.16 & 3.34 & 1.53 \\
HPMC & 0.002 & 4.24 & 3.24 & 1.52 \\
& 0.007 & 3.88 & 2.99 & 1.44 \\
Arabic gum & 0.013 & 3.63 & 2.98 & 1.47 \\
& 0.002 & 4.15 & 3.35 & 1.56 \\
Pectin & 0.007 & 4.10 & 3.28 & 1.58 \\
& 0.013 & 4.20 & 2.99 & 1.63 \\
& 0.002 & 3.96 & 2.96 & 1.64 \\
\end{tabular}

to the products that undergo successive freeze-thaw cycles. Supplementation of several hydrocolloids having different chemical structure and diverse origin to the bread making process was presented by Guarda et al. [10]. The effect of hydrocolloids (sodium alginate, xanthan, $\kappa$-carrageenan, and HPMC) on fresh bread quality and its influence on bread staling was studied. Physical properties (moisture, hardness, and volume) and sensory properties of fresh bread and after storage of $24 \mathrm{~h}$ were analyzed. Hydrocolloids affected the fresh bread quality to different extent and concentrations of $0.1 \%$ (w/w, flour basis) were sufficient for obtaining the observed effects. HPMC was the hydrocolloid which showed improved effect on specific volume index, width/height ratio, and crumb hardness; in addition good sensory properties for visual appearance, aroma, flavor, crunchiness, and overall acceptability were obtained. All hydrocolloids were also able to reduce the moisture loss during bread storage, thereby reducing the dehydration rate of crumb. In addition, during storage alginate and HPMC showed an antistaling effect which retarded the crumb hardening.

Effect of hydrocolloids on dough rheology and bread quality parameters in gluten-free formulations based on rice flour, corn starch, and sodium caseinate (control) was discussed by Lazaridou et al. [1]. During storage of breads a reduction in water activity and increased crumb firmness (compression test) was observed. Compared to the control formulations, crumb firmness was not altered significantly with addition of pectin, carboxymethyl cellulose, and agarose (at 1-2\%) and of $\beta$-glucan (at 1\%); instead, addition of xanthan (1-2\%) as well as $\beta$-glucan (2\%) resulted in crumb hardening.

Effect of pectin, guar gum, and xanthan on properties of gluten-free bread was studied by Gambus et al. [12] The results proved that bread with addition of xanthan had higher volume in comparison with pectin-guar standard. Higher amount of xanthan decreased bread hardness on the day of baking and after seventy-two hours of storage. The amount of free amylose in crumb extract depended on the extent of starch gelatinisation and not on the rate of amylose retrogradation, which was comparable. The degree of starch gelatinisation was influenced by proportions and interactions of pectin, guar gum, and xanthan gum in the mixture of nonstarch hydrocolloids, used as gluten replacers.
Study was conducted by Tavakolipour and KalbasiAshtari [18] to analyze the influence of hydrocolloids (CMC and HPMC) at $0.1,0.3$, and $0.5 \%$ levels on flat bread quality. Although both CMC and HPMC gums enhanced the dough quality by increasing water absorption. The effect of HPMC was more pronounced than CMC.

Antistaling effect of HPMC and $\kappa$-carrageenan was observed in Barbari, an Iranian leavened flat bread [7]. The softening effect of hydrocolloids, mainly HPMC, may be attributed to their water retention capacity. They prevent the amylopectin retrogradation. Moreover, HPMC preferentially binds to starch and decreases the starch-gluten interactions.

Gavilighi et al. [19] investigated the influence of selected hydrocolloids (guar gum, locust bean gum, xanthan gum, and carboxymethyl cellulose) with ratio of $1 \%$ flour basis on the quality of Lavash bread. The results from Differential Scanning Calorimetry and X-Ray Diffraction indicated that, during ageing, greatest enthalpy of retrogradation was observed in control sample, while the lowest was observed in guar gum. Generally, the control sample had the greatest difference in their diffractogram and the highest staling.

Chapattis were prepared by addition of different hydrocolloids like guar gum, xanthan, locust bean gum, and HPMC to the rice flour at levels of 0.25 and $0.5 \%$ flour basis and it was observed that the undesirable textural changes, which take place in chapatti as a result of starch retrogradation, can be delayed by the incorporation of hydrocolloids [20].

Hydrocolloids were incorporated at various levels ranging between $0.25 \%$ and $1.0 \% \mathrm{w} / \mathrm{w}$ of whole wheat flour. Amongst the hydrocolloids studied, guar gum prevented staling of chapattis and chapattis possessed excellent pliability [21].

\section{Major Flat Breads}

2.1. Characteristics of Flat Bread. Different characteristics of flat breads are as follows: they have lower specific volumes than pan breads, the leavened flat breads are made with a shorter fermentation period in comparison to pan bread, and flat breads are made with a higher baking temperature and shorter baking times [22]. Flat breads are usually round in shape but are sometimes triangular or rectangular. Their diameters can vary from 2-3 inches to 25 inches, their 


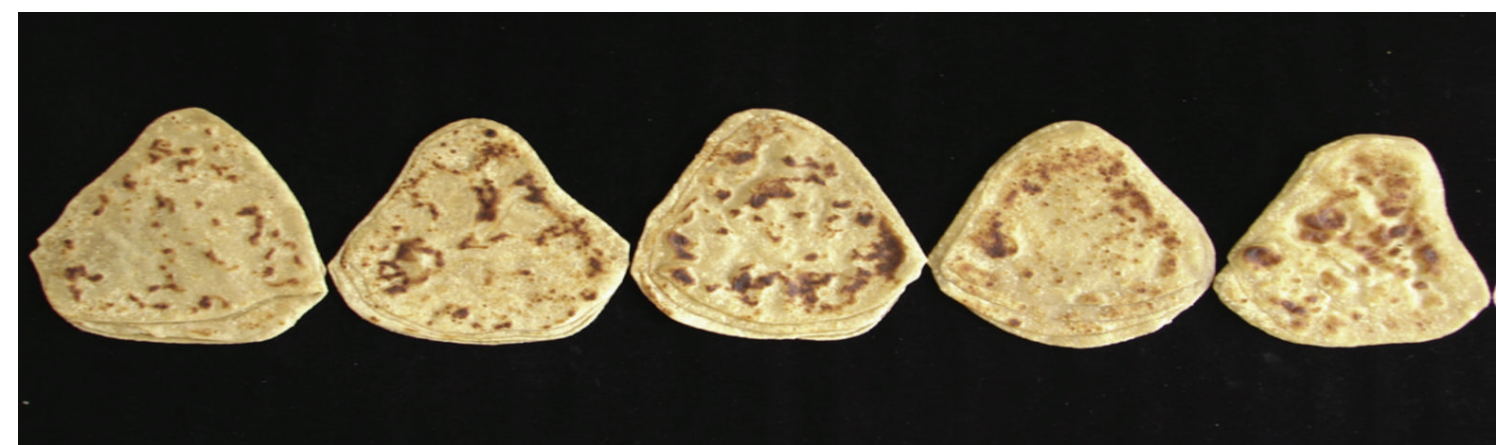

(a)

(b)

(c)

(d)

(e)

FIGURE 1: North Indian parottas with different levels of multigrain blend (MGB). (a) Control (0 g/100 g MGB); (b) $10 \mathrm{~g} / 100 \mathrm{~g}$ MGB; (c) $20 \mathrm{~g} / 100 \mathrm{~g}$ MGB; (d) $30 \mathrm{~g} / 100 \mathrm{~g}$ MGB; (e) $40 \mathrm{~g} / 100 \mathrm{~g}$ MGB [28].

thicknesses vary from paper thin to 1 inch, and their crust is very thin and light with brown or dark spots. They have a higher crust : crumb ratio than do pan breads [23].

Flat breads can be categorized into two groups as one (single) layered or two (double) layered. Another two subgroups for single-layered flat breads are leavened or unleavened. Barbari, gomme, tandýr, pide, and so forth are classified as leavened single-layered flat bread; Lavash, puri, chapatti, and parotta are classified as unleavened single-layered flat bread; and Arabic (pita), balady, and so forth are two-layered flat bread [24].

\subsection{Production Steps of Flat Bread. Optimum mixing is} required for high quality flat and pan breads. If the flour is too strong, overmixing improves bread quality by mechanical degradation of gluten structure. Soft and moist dough generally forms an excellent pocket during baking at $482^{\circ} \mathrm{C}$ to $537.78^{\circ} \mathrm{C}$ [23]. Flat breads generally require less fermentation than white pan breads. Most flat breads are made using high extraction or near whole wheat flour using little or no fermentation. This produces bread with high fiber and phytate content that may be complex with bivalent metals and poses no danger to consumers in the western world, where bread is one of the major parts of the diet. One of the crucial steps in flat bread production is the flattening and sheeting of the dough. Dough pieces are made spherical in order to get a gas retention capability and good flattening. The sheeting step aids in removal of the gas inside its structure. The optimum dough thickness is $2-10 \mathrm{~mm}$. Variation in flat bread thickness affects the quality to a great extent [22]. Proof time for flat bread is usually very short or sometimes omitted entirely. Pan breads are baked at a lower temperature for a longer period. Flat breads require a very short baking time of 1-10 min at high temperature. Short baking time also aids in retaining high bread moisture and softness [24].

\section{Types of Flat Breads Produced All Over the World}

3.1. Parotta. Characteristics such as flexible hand-feel, soft and slightly chewy texture, distinct layers, easy disintegration in the mouth, and typical pleasant taste and aroma are the pleasing characteristics of parotta [25]. North Indian parotta is unleavened flat bread prepared from whole wheat flour, salt, refined oil, and water. The dough is sheeted and laminated at least twice, contains 4-6 discrete layers, and is slightly thicker than chapatti. Parotta is prepared in most of the Indian homes. Normally, it is prepared from whole wheat flour with $2.5 \%$ salt, $65 \%$ water, and $40 \%$ shortening. After mixing, the dough is sheeted on the board with rolling pin and shaped round, square, or triangular. The sheeted dough (round) is smeared with fat and folded several times and again flattened. The baking is done on preheated hot iron plate (Tawa) on both sides of bread [26].

The effect of hydrocolloids, namely, Arabic (AR), guar (GR), xanthan (XN), carrageenan (CG), and hydroxypropyl methylcellulose (HPMC) on the rheological, microstructural, and quality characteristics of south Indian parotta was studied separately at the level of $0.5 \%$. Addition of hydrocolloids improved the shape of parottas and reduced the shear force. Among the hydrocolloids tried, GR brought about the greatest improvement in the quality of parotta, followed in HPMC $>$ XN $>$ CG $>$ AR [27].

North Indian parotta was prepared from whole wheat flour which was replaced with multigrain blend (MGB) (chick pea split without husk, barley, soya bean, and fenugreek seeds) at 10, 20, 30, and $40 \mathrm{~g} / 100 \mathrm{~g}$. Figure 1 presents the North Indian parottas with different levels of multigrain blend (MGB). Addition of multigrains increased the protein, fat, dietary fiber, and mineral contents of north Indian parotta [28].

3.2. Puri. Puri or poori is a traditional unleavened fried product prepared from whole wheat flour particularly in South Asia including India, Pakistan, and Bangladesh. It is consumed as breakfast, or as a snack or light meal. In recent years, efforts are being made to reduce the fat/oil absorption during deep-fat frying [30]. Puri which contains flour/whole wheat flour and fat is made from slightly hard doughs. The flattened dough is lowered gently into preheated oil and then it is pressed with the help of a slotted spatula to achieve full puffing [26]. In puri production, all the ingredients are mixed 
and kneaded into a fully developed dough. The dough is then scaled, divided, rounded, sheeted to a thickness of $1.5 \mathrm{~mm}$, cut into a circular disc of $12-14 \mathrm{~cm}$, and deep-fat-fried in preheated oil at $180-200^{\circ} \mathrm{C}$ for $10 \mathrm{~s}$ on one side and $15 \mathrm{~s}$ on the other side. Fried puri after draining the oil for $30 \mathrm{~s}$ is cooled for $10 \mathrm{~min}$ [31].

Effect of hydrocolloids such as guar gum (GG), Arabic gum (AG), carrageenan (CG), locust bean gum (LBG), xanthan gum (XN), hydroxypropyl methylcellulose (HPMC), and carboxymethyl cellulose (CMC) at $0.5 \% \mathrm{w} / \mathrm{w}$ level on rheological and quality parameters of puri from whole wheat flour was studied. In general, hydrocolloids helped in retention of moisture in the puri and hence it remained softer and pliable, while they reduced the oil content of puri. This was attributed to the thermal gelation of these hydrocolloids at the frying temperature, which creates an oil resistant film around the fried food and thereby lowered the oil absorption [31].

Sudha and Rao [32] reported that addition of HPMC at 0.5 and $1.0 \% \mathrm{w} / \mathrm{w}$ increased the water absorption and dough stability. It has also helped in moisture retention and hence resulted in highly pliable and soft-textured puri. Scanning electron micrographs of puri dough revealed that after addition of HPMC, the starch granules were seen to be coated.

3.3. Chapatti. Chapatti is the oldest and the most popular bread in the world [33]. Chapatti, a flat unleavened Indian bread made of whole wheat flour, is traditionally prepared in households by hand sheeting of dough followed by baking on hot griddle and is consumed fresh. The unfavourable changes in chapatti during storage occur due to retrogradation of the starch [34]. Staling can be controlled by the use of hydrocolloids.

Effect of various hydrocolloids (guar gum, carboxymethyl cellulose (CMC), $\kappa$-carrageenan, and hydroxypropyl methylcellulose (HPMC)) on fresh chapatti quality as well as on stored chapatti texture was investigated by Ghodke Shalini and Laxmi [21]. Hydrocolloids were incorporated at various levels ranging between $0.25 \%$ and $1.0 \% \mathrm{w} / \mathrm{w}$ of whole wheat flour. Amongst the hydrocolloids studied, guar gum gave the highest extensibility for fresh and stored chapatti. The force required to tear the fresh chapatti was decreased with hydrocolloid addition; however, guar gum addition at $0.75 \% \mathrm{w} / \mathrm{w}$ of whole wheat flour gave the softest chapatti. Extensibility of stored chapatti significantly decreased with storage both at room and at refrigeration temperature; however refrigerated chapatti containing guar gum showed less loss in extensibility up to a period of 2 days. There was no significant effect on colour of chapattis due to the addition of hydrocolloids and sensory acceptability was found to be higher than that of control.

Gujral et al. [20] studied that addition of different hydrocolloids like guar gum, xanthan, locust bean gum, and hydroxypropyl methylcellulose to the rice flour at levels of 0.25 and $0.5 \%$ flour basis improved the texture of chapatti by keeping it more extensible (pliable and less brittle) during storage. Xanthan and GG may act as strong water binder effectively depriving the starch chain of usable water for recrystallization.

Khan et al. [35] investigated the effect of different additives such as CMC (carboxymethyl cellulose), ascorbic acid, lecithin, and sodium propionate on the dough, chapatti making characteristics and also checked the staling of chapatti. It was observed that almost all the additives tested increased the water absorption as compared to control. The water absorption was highest in case of CMC. CMC and lecithin improved the pasting property, water absorption capacity, dough development time, and dough stability of wheat flour and improved most of the sensory attributes of chapattis, while the synergistic effect of all the additives reduced the mould growth and improved almost all the sensory attributes as compared to the control.

3.4. Lavash. Lavash can be defined as single-layered and unleavened flat bread that has an oval or rectangular (60$70 \mathrm{~cm}$ long, $30-40 \mathrm{~cm}$ wide) shape and a 2 to $3 \mathrm{~mm}$ thickness with a creamy white colour and small blisters distributed over the whole surface. Tavakolipour and Kalbasi-Ashtari [18] investigated the physical and rheological properties of mixing CMC and HPMC at different concentrations with wheat flour of Sorkheh and Sardary varieties. Incorporation of hydrocolloids increased the dough resistance. Sensory evaluation of Lavash bread showed that separate addition of CMC and HPMC at 0.5\% level in Sardary flour and at $0.3 \%$ level in Sorkheh flour raised their sensory scores significantly. It was found that hydrocolloids (such as CMC and HPMC) decrease the rate of increase in rigidity of bread compared to control and increase freshness of Arabian bread for 4 days of storage.

3.5. Barbari. Barbari is one of the most popular flat breads widely consumed in the northern and north-western parts of Iran. It is leavened and thicker oval bread. The bread is usually 70 to $80 \mathrm{~cm}$ long and 25 to $30 \mathrm{~cm}$ wide with a thickness of about $3.5 \mathrm{~cm}$. All its ingredients are mixed to proper consistency and fermented for two hours. Dough balls are flattened into an oval shape and rested for 20 minutes [36]. The brown colour gets developed from the use of Romal. Romal is made from flour, baking soda, mixed in the boiling water, which then turns the starch of the flour into dextrin, which makes the golden colour. The dough is then docked and five or six one-centimetre deep rows are formed with fingers, primarily for decorative purpose. Final proof and baking times are often 15 and 8-12 minutes, respectively [7].

Effect of five different alternate flour types (amaranth, barley, DDGS (distillers dried grains with soluble), oat, and rye) on chemical and physical properties of the Barbari bread was studied by Pourafshar et al. [36]. It was determined that bread made with 20 percent DDGS and 80 percent of wheat flour had the highest fiber and moisture content. The bread made with amaranth had the highest ash content, while the one made with rye had the highest protein and fat content.

Ghanbari and Farmani [7] investigated the effect of various hydrocolloids including hydroxypropyl methylcellulose (HPMC), xanthan, and $\kappa$-carrageenan at 0.2 and $0.5 \%$ levels 
on dough rheological properties, fresh bread quality, and bread staling. HPMC had the highest effect on dough water absorption. Addition of xanthan gum at $0.5 \%$ level showed an increase in dough stability, while the other treatments showed a reduction in the stability of the dough. HPMC produced higher extensibility than control whereas dough samples containing $\kappa$-carrageenan or xanthan had shorter. As compared to control, $\kappa$-carrageenan or HPMC at 0.2 and $0.5 \%$ levels delayed staling. Addition of hydrocolloids to the bread formulation could also improve the sensory properties of Barbari bread.

Moazzezi et al. [37] investigated the effect of apple fiber (5\%, $8 \%$, and $11 \%)$ and $\mathrm{CMC}(0.1 \%$ and $0.5 \%-\mathrm{w} / \mathrm{w})$ on the rheological and staling properties of traditional Barbari bread. In comparison to control, the flat bread containing $11 \%$ apple fiber and 0.5\% CMC showed higher water absorption capacity (69.35\%), lower degree of softening (19.0 B.U.), and higher quality properties (113.0). The results of extensograph revealed that, during fermentation of bread samples at 45,90 , and $135 \mathrm{~min}$, bread samples with $5 \%, 8 \%$, and $11 \%$ level of apple fiber and $0.5 \%$ of CMC showed the highest amounts of energy, as compared to other experimental samples. The results of sensory evaluation proved that sample with highest level of apple fiber and CMC had the highest overall acceptability and lowest staling after $72 \mathrm{~h}$ storage.

Majzoobi et al. [38] studied the quality of Barbari dough and bread (Iranian flat bread) in terms of texture, taste, and general acceptability of fresh bread. The study involved incorporation of microcrystalline cellulose and hydroxypropyl methyl cellulose at $0.5 \%$ wheat flour basis. The results revealed that hydroxypropyl methyl cellulose produced higher water absorption, improved dough stability time, softer bread texture, and higher volume, as well as greater acceptability mainly due to its more hydrophilic molecular property.

Glazing is a surface coating method to improve the quality of bakery products. Effect of hydrocolloids as glazing agent was studied on Barbari flat bread. It was found that water activity increased. Also, xanthan treatment provided the greatest effect on the specific volume and moisture content of fresh bread. Guar gum treatments had more significant effect on width/height ratio in comparison to unglazed bread. Evaluation of the hydrocolloid glazing group showed that crumb moistures revealed that guar gum had no effect, while the starch had the most crumb moisture [39].

3.6. Sangak Bread. Sangak is a sourdough flat bread, 70$80 \mathrm{~cm}$ long, $40-50 \mathrm{~cm}$ wide, and $3-5 \mathrm{~mm}$ thick; its surface is sprinkled with sesame or poppy seeds and is the most popular bread in Iran. Flour of $95 \%$ extraction rate, salt $(1.5 \%)$, sourdough $(20 \%)$, yeast $(0.5 \%)$, and water $(85 \%)$ are mixed to proper consistency and fermented for two hours. The dough is usually made from flour with strong protein quality and its paste is more similar to batter rather than the dough of other flat breads. A portion of the dough $(500 \mathrm{~g})$ is sheeted on a special convex peddle, docked, and transferred onto the hot pebbles of the oven. The temperature of pebbles varies from 350 to $500^{\circ} \mathrm{C}$ and the baking time from 2 to $4 \mathrm{~min}$ [33].
Rahnama et al. [40] investigated the potential of fenugreek gum for the improvement of the quality of Sangak flat bread. The results of Farinograph revealed that the dough formulated with $5.5 \% \mathrm{w} / \mathrm{w}$ fenugreek gum and leavened for $2.6 \mathrm{hr}$ yielded to maximum dough water absorption, dough development time, stability time, and extensibility values. In comparison to control, the bread baked with fenugreek gum incorporated dough had higher moisture content, loaf volume, softness, and lightness than control bread. Sensory evaluation indicated that overall acceptability to formulation supplemented with 5.5\% fenugreek gum showed the highest score.

3.7. Balady Bread. Wheaten, pocket-type flat breads are referred to as "Arabic," balady, shami, "Lebanese," and mafrood in the Arab countries and as "pita" in the United States and Europe.

In Egypt, bread is the main staple. The most popular wheat bread is a flat, circular loaf composed of two layers called balady bread. Effect of baking time and temperature on bread quality, starch gelatinization, and staling was studied by Faridi and Rubenthaler [23]. Flour extraction rate was high (82 percent). Four levels of baking time and temperature $\left(540^{\circ} \mathrm{C}, 1 \mathrm{~min} ; 415^{\circ} \mathrm{C} 2 \mathrm{~min} ; 37^{\circ} \mathrm{C}, 3-4 \mathrm{~min} ; 260^{\circ} \mathrm{C}, 6-7 \mathrm{~min}\right)$ were used to bake dough. Lower oven temperature and longer baking time produced breads that were drier and of lower quality. Pasting properties and alkaline water retention capacity were faster for breads baked at $260^{\circ} \mathrm{C}$ for $6-7 \mathrm{~min}$ than those baked at higher temperature and shorter time. Staling rate was faster during the first eight hours of storage.

Mahmoud et al. [41] studied the influence of specific hydrocolloids (xanthan gum and guar gum) at varying levels which was observed on the quality of gluten-free balady flat bread formulation based on rice flour, corn, and potato starch blends. In comparison to control, gums improved the weight and roundness of breads. Hydrocolloids also extended the shelf-life and staling was retarded after $72 \mathrm{hr}$ of storage at room temperature.

3.8. Pita Bread. Pita bread is a common staple in Middle Eastern countries and has enjoyed considerable and increasing popularity in other areas of the world. This popularity is due to the convenience of using bread for making a sandwich, since the bread forms a pocket which may be filled with meat, cheese, and other edible material. In its most common form, pita bread is in the shape of a large flat pancake, typically four to eight inches in diameter and one-eighth to three-eighths inches in thickness. Figure 2 presents traditional Egyptian pita bread. In the baking process, the dough form seals and inflates to form the central void characteristic of pita bread, which is easily torn at the perforation [42]. Toufeili et al. [42] analyzed the effect of methylcellulose, egg albumen, and gum Arabic on the sensory properties of gluten-free pocket-type flat bread baked from formulas incorporating pregelatinized rice flour and pregelatinized corn starch with corn flour. The results indicated that gum Arabic at higher levels produced cohesive product, while at lower levels it produced less cohesive and a product inferior to wheat bread in rollability. 


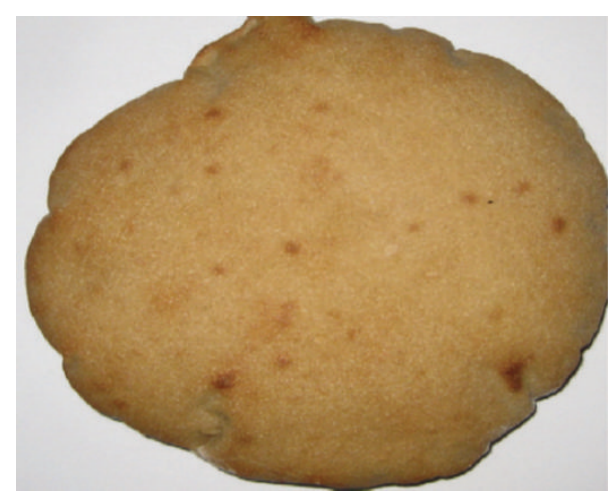

(a)

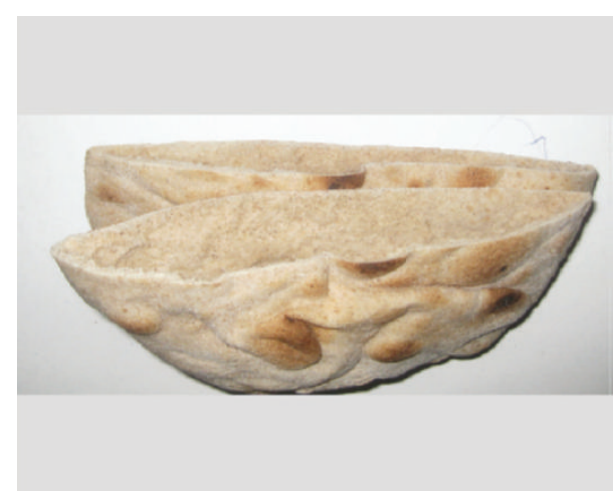

(b)

FIgURE 2: Traditional Egyptian pita bread ((a) from above, (b) cut open) [29].

Loaves which were baked from formulations with levels of methylcellulose between 1.71 and $3.16 \mathrm{~g}$ and egg albumen levels between 1.90 and $3.18 \mathrm{~g}$ were compatible with those of wheat bread in rollability, tearing, first bite hardness, adhesiveness, and masticatory hardness. All breads possessed a strong corn flavor, a light-yellow and a less grainy crumb with apparent waxy patches, and a faster staling rate than that of regular wheat bread.

\section{Conclusion}

Flat breads are popular all over the world. They are made either leavened or unleavened. They are also divided into two major groups: one (single) layered and two (double) layered.

The present study revealed that flat breads could be made by adding hydrocolloids to improve rheological, microstructural, and quality characteristics. Hydrocolloids comprise a number of water-soluble polysaccharides providing a range of functional properties. Dough water absorption, which has a great effect on bread quality and its shelf-life, was increased by all hydrocolloids. Furthermore, it was observed that addition of hydrocolloids to the flat bread formulation could also improve the sensory properties and prevent staling.

\section{Conflict of Interests}

The authors declare that there is no conflict of interests regarding the publication of this paper.

\section{References}

[1] A. Lazaridou, D. Duta, M. Papageorgiou, N. Belc, and C. G. Biliaderis, "Effects of hydrocolloids on dough rheology and bread quality parameters in gluten-free formulations," Journal of Food Engineering, vol. 79, no. 3, pp. 1033-1047, 2007.

[2] A. Krüger, C. Ferrero, and N. E. Zaritzky, "Modelling corn starch swelling in batch systems: effect of sucrose and hydrocolloids," Journal of Food Engineering, vol. 58, no. 2, pp. 125-133, 2003.

[3] C. M. Rosell, J. A. Rojas, and C. Benedito de Barber, "Influence of hydrocolloids on dough rheology and bread quality," Food Hydrocolloids, vol. 15, no. 1, pp. 75-81, 2001.
[4] J. N. BeMiller, "Pasting, paste, and gel properties of starchhydrocolloid combinations," Carbohydrate Polymers, vol. 86, no. 2, pp. 386-423, 2011.

[5] S. Satrapai and M. Suphantharika, "Influence of spent brewer's yeast $\beta$-glucan on gelatinization and retrogradation of rice starch," Carbohydrate Polymers, vol. 67, no. 4, pp. 500-510, 2007.

[6] P. Achayuthakan and M. Suphantharika, "Pasting and rheological properties of waxy corn starch as affected by guar gum and xanthan gum," Carbohydrate Polymers, vol. 71, no. 1, pp. 9-17, 2008.

[7] M. Ghanbari and J. Farmani, "Influence of hydrocolloids on dough properties and quality of barbari: an Iranian leavened flat bread," Journal of Agricultural Science and Technology, vol. 15, no. 3, pp. 545-555, 2013.

[8] A. B. Rodge, S. M. Sonkamble, R. V. Salve, and S. I. Hashmi, "Effect of hydrocolloid (guar gum) incorporation on the quality characteristics of bread," Journal of Food Processing and Technology, vol. 3, no. 2, pp. 1-7, 2012.

[9] H. Gambus, A. Nowotna, R. Ziobro, D. Gumul, and M. Sikora, "The effect of use of guar gum with pectin mixtures in glutenfree bread," Electronic Journal of Polish Agricultural Universities, vol. 4, no. 2, pp. 61-74, 2001.

[10] A. Guarda, C. M. Rosell, C. Benedito, and M. J. Galotto, "Different hydrocolloids as bread improvers and antistaling agents," Food Hydrocolloids, vol. 18, no. 2, pp. 241-247, 2004.

[11] S. S. Schwarzlaff, J. M. Johnson, W. E. Barbeau, and S. Duncan, "Guar and locust bean gums as partial replacers of all-purpose flour in bread: an objective and sensory evaluation," Journal of Food Quality, vol. 19, no. 3, pp. 217-229, 1996.

[12] H. Gambus, A. Nowotna, R. Ziobro, D. Gumul, and M. Sikoro, "The effect of use of guar gum with pectin mixture in glutenfree bread," Electronic Journal of Polish Agricultural Universities, vol. 4, no. 2, pp. 61-74, 2001.

[13] A.-S. Hager and E. K. Arendt, "Influence of hydroxypropylmethylcellulose (HPMC), xanthan gum and their combination on loaf specific volume, crumb hardness and crumb grain characteristics of gluten-free breads based on rice, maize, teff and buckwheat," Food Hydrocolloids, vol. 32, no. 1, pp. 195-203, 2013.

[14] V. Tolstoguzov, "Some thermodynamic considerations in food formulation," Food Hydrocolloids, vol. 17, no. 1, pp. 1-23, 2003.

[15] A. E. León, P. D. Ribotta, S. F. Ausar, C. Fernández, C. A. Landa, and D. M. Beltramo, "Interactions of different carrageenan 
isoforms and flour components in breadmaking," Journal of Agricultural and Food Chemistry, vol. 48, no. 7, pp. 2634-2638, 2000.

[16] M. E. Bárcenas, J. De la O-Kelle, and C. M. Rosell, "Influence of different hydrocolloids on major wheat dough components (gluten and starch)," Journal of Food Engineering, vol. 94, no. 34, pp. 241-247, 2009.

[17] P. D. Ribotta, S. F. Ausar, D. M. Beltramo, and A. E. León, "Interactions of hydrocolloids and sonicated-gluten proteins," Food Hydrocolloids, vol. 19, no. 1, pp. 93-99, 2005.

[18] H. Tavakolipour and A. Kalbasi-Ashtari, "Influence of gums on dough properties and flat bread quality of two persian wheat varieties," Journal of Food Process Engineering, vol. 30, no. 1, pp. 74-87, 2007.

[19] H. A. Gavilighi, M. H. Azizi, M. Barzegar, and M. A. Ameri, "Effect of selected hydrocolloids on bread staling as evaluated by DSC and XRD," Journal of Food Technology, vol. 4, no. 3, pp. 185-188, 2006.

[20] H. S. Gujral, M. Haros, and C. M. Rosell, "Improving the texture and delaying staling in rice flour chapati with hydrocolloids and $\alpha$-amylase," Journal of Food Engineering, vol. 65, no. 1, pp. 89-94, 2004.

[21] K. G. Ghodke Shalini and A. Laxmi, "Influence of additives on rheological characteristics of whole-wheat dough and quality of chapatti (Indian unleavened Flat bread) Part I-hydrocolloids," Food Hydrocolloids, vol. 21, no. 1, pp. 110-117, 2007.

[22] Y. Coskuner, E. Karababa, and R. Ercan, "Flat bread production technology," Journal of Food, vol. 24, pp. 83-97, 1999.

[23] H. A. Faridi and G. L. Rubenthaler, "Ancient breads and a new science: understanding flat breads [taste, flavor, texture and appearance]," Cereal Foods World, vol. 28, no. 10, pp. 627-629, 1983.

[24] D. Gocmen, A. N. Inkaya, and E. Aydin, "Flat breads," Bulgarian Journal of Agricultural Science, vol. 15, no. 4, pp. 298-306, 2009.

[25] D. Indrani, S. J. Rao, K. U. Sankar, and G. V. Rao, "Changes in the physical-chemical and organoleptic characteristics of parotta during storage," Food Research International, vol. 33, no. 5, pp. 323-329, 2000.

[26] S. A. Mir, H. R. Naik, M. A. Shah, M. M. Mir, M. H. Wani, and M. A. Bhat, "Indian flat breads: a review," Food and Nutrition Sciences, vol. 5, no. 6, pp. 549-561, 2014.

[27] S. Smitha, J. Rajiv, K. Begum, and D. Indrani, "Effect of hydrocolloids on rheological, microstructural and quality characteristics of parotta- an unleavened Indian flat bread," Journal of Texture Studies, vol. 39, no. 3, pp. 267-283, 2008.

[28] D. Indrani, P. Swetha, C. Soumya, J. Rajiv, and G. V. Rao, "Effect of multigrains on rheological, microstructural and quality characteristics of north Indian parotta-an Indian flat bread," LWT_Food Science and Technology, vol. 44, no. 3, pp. 719-724, 2011.

[29] M. Hefni and C. M. Witthöft, "Enhancement of the folate content in Egyptian pita bread," Food and Nutrition Research, vol. 56, 2012.

[30] R. Priya, R. S. Singhal, and P. R. Kulkarni, "Carboxymethylcellulose and hydroxypropylmethylcellulose as additives in reduction of oil content in batter based deep-fat fried boondis," Carbohydrate Polymers, vol. 29, no. 4, pp. 333-336, 1996.

[31] K. R. Parimala and M. L. Sudha, "Effect of hydrocolloids on the rheological, microscopic, mass transfer characteristics during frying and quality characteristics of puri," Food Hydrocolloids, vol. 27, no. 1, pp. 191-200, 2012.
[32] M. L. Sudha and G. V. Rao, "Influence of hydroxypropyl methylcellulose on the rheological and microstructural characteristics of whole wheat flour dough and quality of puri," Journal of Texture Studies, vol. 40, no. 2, pp. 172-191, 2009.

[33] J. Qarooni, "Flat breads," American Institute of Baking Research Department Technical Bulletin, vol. 21, no. 1, 1990.

[34] J. A. Gray and J. N. Bemiller, "Bread staling: molecular basis and control," Comprehensive Reviews in Food Science and Food Safety, vol. 2, no. 1, pp. 1-21, 2003.

[35] A. N. Khan, A. Ahmed, M. S. Bhatti, M. A. Randhawa, A. Ahmad, and A. A. Yousaf, "Effect of additives on the shelf life extension of chapatti," Food Science and Technology Research, vol. 17, no. 3, pp. 203-208, 2011.

[36] S. Pourafshar, P. Krishnan, and K. A. Rosentrater, "Using alternative flours as partial replacement in barbari bread (traditional Iranian bread) formulation," in Proceedings of the Annual International Meeting (ASABE '11), Louisville, KY, USA, August 2011.

[37] S. Moazzezi, S. M. Seyedain, and L. Nateghi, "Rheological properties of barbari bread containing apple pomace and carboxy methyl cellulose," Life Science Journal, vol. 9, no. 3, pp. 1318-1325, 2012.

[38] M. Majzoobi, A. Farahnaky, and R. Ostovan, "Effects of microcrystalline cellulose and hydroxypropylmethyl cellulose on the properties of dough and flat bread (Iranian Barbari Bread)," Iran Agricultural Research, vol. 25, no. 1-2, pp. 87-98, 2007.

[39] S. H. R. Jahromi, F. T. Yazdi, M. Karimi et al., "Application of glazing for bread quality improvement," Food and Bioprocess Technology, vol. 5, no. 6, pp. 2381-2391, 2012.

[40] F. Rahnama, J. Mohammadzadeh Milani, and A. Gohari Ardabili, "Improved quality characteristics of Sangak bread by response surface optimisation of farinograph and extensograph traits of doughs formulated with fenugreek gum," Quality Assurance and Safety of Crops \& Foods, vol. 7, no. 4, pp. 413-421, 2015.

[41] R. M. Mahmoud, E. I. Yousif, M. G. E. Gadallah, and A. R. Alawneh, "Formulations and quality characterization of glutenfree Egyptian balady flat bread," Annals of Agricultural Sciences, vol. 58, no. 1, pp. 19-25, 2013.

[42] I. Toufeili, S. Dagher, S. Shadarevian, A. Noureddine, M. Sarakbi, and M. T. Farran, "Formulation of gluten-free pockettype flat breads: optimization of methylcellulose, gum Arabic, and egg albumen levels by response surface methodology," Cereal Chemistry, vol. 71, no. 6, pp. 594-600, 1994. 

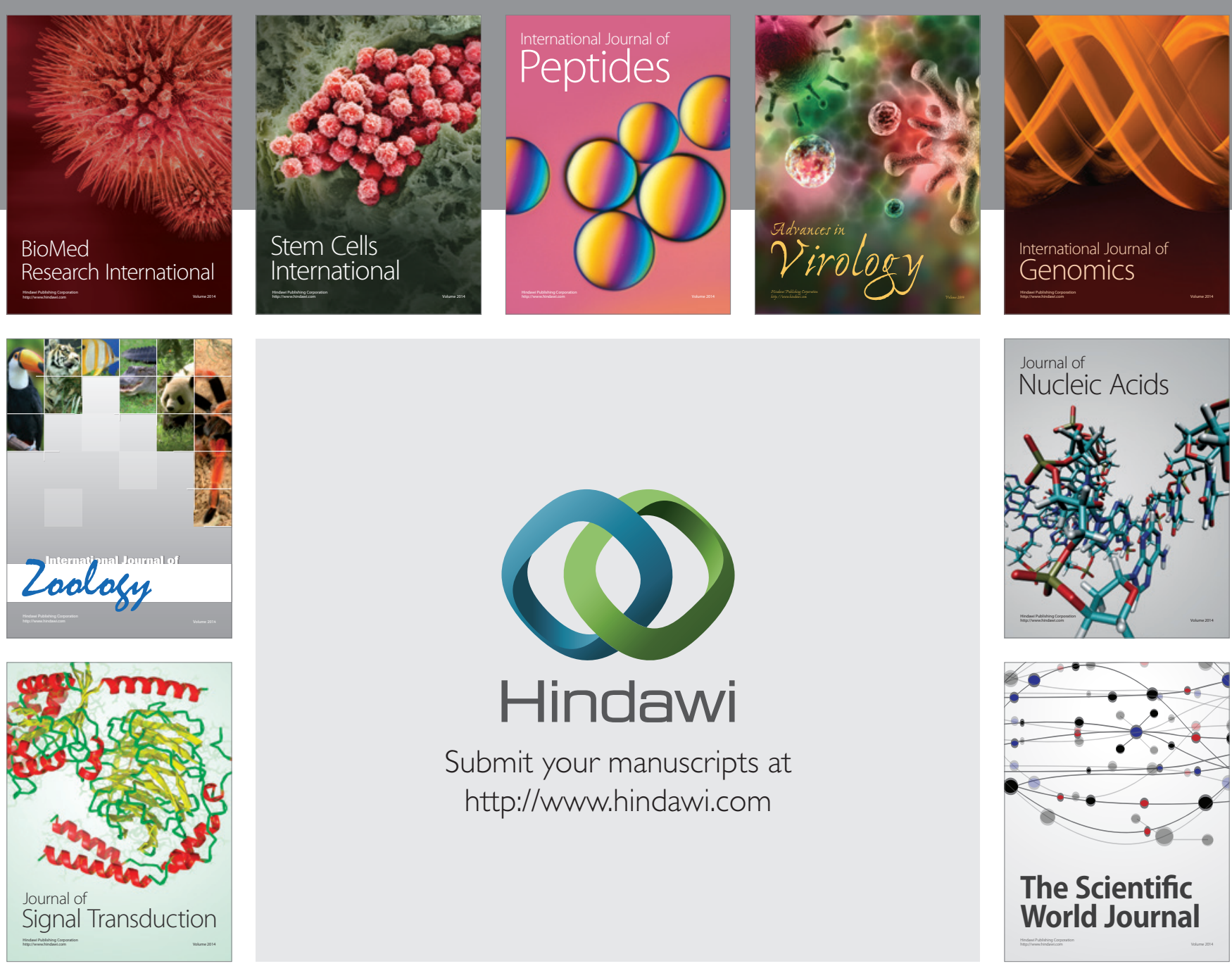

Submit your manuscripts at

http://www.hindawi.com
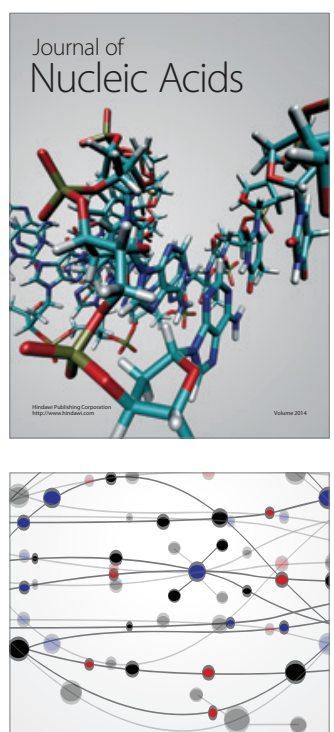

The Scientific World Journal
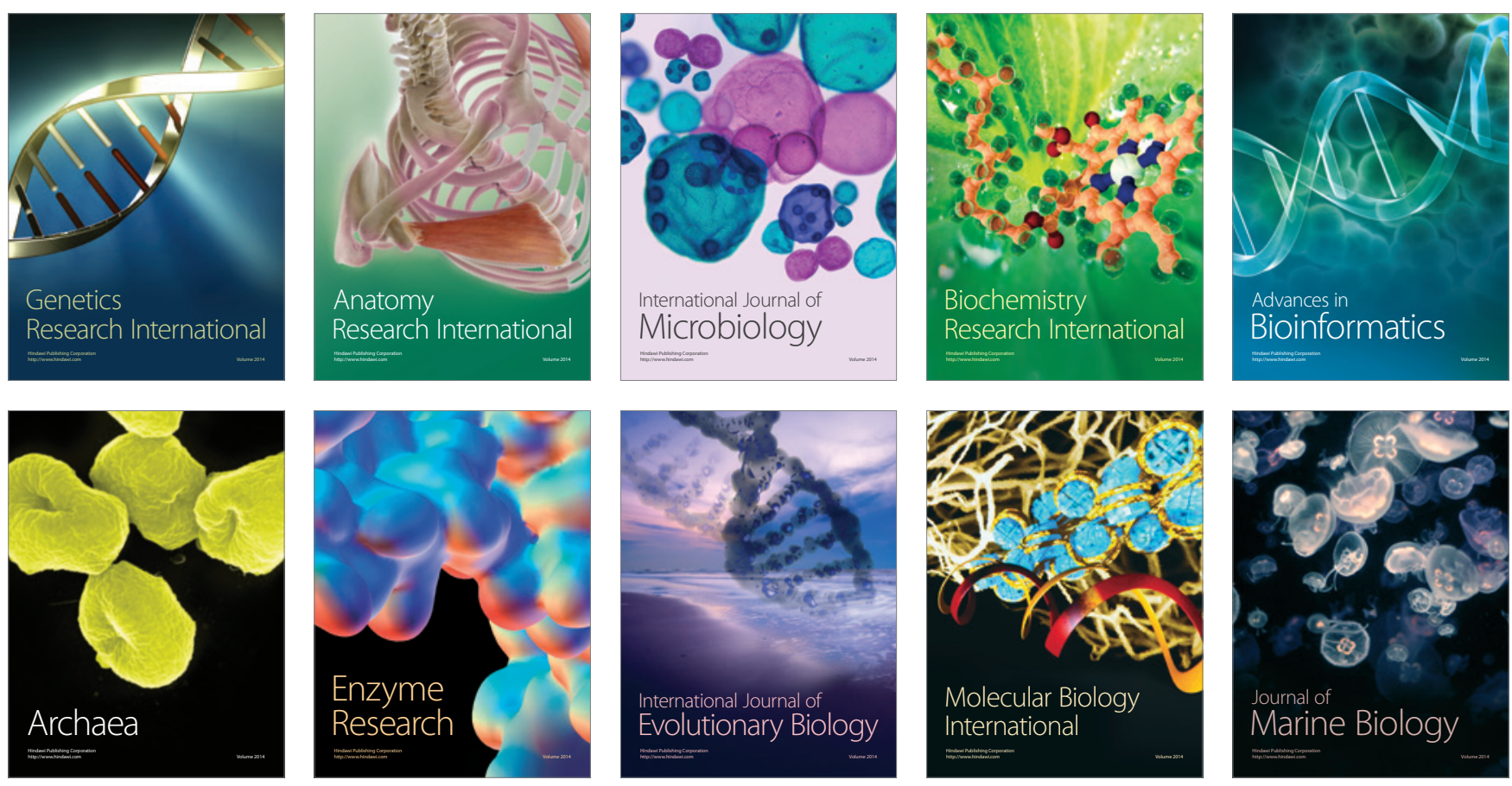